\title{
Investigation of hTERT Expression Level and its Relation with Clinicopathological Features and Resistance to Chemotherapy in Colorectal Cancer Patients
}

\author{
Samira Shabani ${ }^{1}$, Frouzandeh Mahjoubi ${ }^{1 *}$, Bahar Mahjoubi² and Rezvan Mirzaee ${ }^{2}$
}

${ }^{1}$ Medical Biotechnology Division, National Institute of Genetic Engineering and Biotechnology (NIGEB), Iran

${ }^{2}$ Hazrat Rasool Hospital, Tehran University of Medical Sciences and Health Care Services, Tehran, Iran

\begin{abstract}
One of the most common causes of mortality in the world is cancer. In spite of advancement in cancer treatments, the clinical outcome is far away from expectation yet. Drug resistance remains a major obstacle to the effective cure of almost all of the cancers. Telomerase is a ribonucleoprotein enzyme that contains an extremely conserved reverse transcriptase (TERT) component and a template RNA component (TERC or TR). Telomerase activity is infrequently present in normal somatic cells, but it is observed in most cancer cells. This enzyme is actually a key enzyme for human cells to acquire immortality. This study was conducted to investigate possible association between telomerase expression and clinicopathological features as well as the feasible correlation between telomerase expression and clinical response to chemotherapy in Iranian colorectal cancer patients.

In this regards tumoral and adjacent normal tissues of 50 colon cancer patients were assessed for the expression level of telomerase quantitative PCR. A significant correlation was found between telomerase expression level and the stage of cancer. hTERT expression level was significantly increased in early stage tumors.

No association was seen between telomerase expression and other clinical features such as age, size of the tumor, lymph node involvement. Regarding to the observations, it seems expression changes of hTERT can be employed as an important marker in the diagnosis of human colorectal cancer at an early stage after performing some complementary tests.
\end{abstract}

Keywords: Colorectal cancer; Telomerase; Quantitative PCR

\section{Introduction}

Colorectal cancer (CRC) is the fourth frequent cancer in males and the third in the female [1,2]. In Iran the rate of colorectal cancer is (7 per 100,000 population or 5000 individuals) yearly and this cancer is the third widespread cancer in women and fifth in men $[1,2]$. The current treatment for nearly all of cancers is in the base of chemotherapy. However, drug resistance limits the efficiency of chemotherapy [3].Various strategies are currently being examined to conquer drug resistance, but there were no significant success in the clinic [4]. One of the main reasons for the failure in cancer treatment is immortalization [5]. Several evidence signify that telomeres protecting the ends of chromosomes are centrally involved in the capability for immortalization [6,7]. The majority of cancers and cancer cell lines maintain their telomeres via telomerase [8]. Telomerase is a ribonucleoprotein enzyme which contains an extremely conserved reverse transcriptase (TERT) and a template RNA component (TERC or TR).TERT is the catalytic subunit of the telomerase and uses the 3 telomere overhang as a primer to align with TR sequences, TERT adds telomeric repeats to chromosome ends, So its primary function is maintenance and denovo synthesis of telomers at the end of linear chromosomes $[9,10]$.

Although the role of telomerase in inducing drug resistance in several cancers has been extensively investigated the data is still controversial [11-13]. According to the above description, evaluation of the telomerase expression level in colorectal cancer patients seems reasonable. Therefore, the aim of the present study was to investigate the possible correlation between telomerase expression level and clinicopathological features. We also wished to see whether or not telomerase is associated with drug resistance in Iranian CRC patients.

\section{Material and Method}

\section{Patients}

This project was approved by the National Institute for Genetic Engineering and Biotechnology (NIGEB) and written informed consent was obtained from all patients. Fifty patients with colorectal cancer admitted to Hazrat Rasol Hospital in Tehran were enrolled in this study and underwent surgery. Fresh tissues (tumor and normal tissue adjacent to the tumor) were collected by the clinicians in separate sterile tubes. Tissue samples were frozen and stored at $-70^{\circ} \mathrm{C}$. The pathological information of all patients was obtained from Pathology Department of Hazrat Rasoll Hospital. Staging of colorectal cancer was performed according to the International Union against Cancer (UICC) which is based on (AJCC-TNM) classification [14].

The patients were followed up clinically for at least 2 years. Clinical response was assessed by evaluating carcino embryonic antigen (CEA) levels at 3 month intervals; clinical examination and ultrasonography

*Corresponding author: Frouzandeh Mahjoubi, Medical Biotechnology Division, National Institute of Genetic Engineering and Biotechnology (NIGEB), Pajouhesh Blv, Tehran Karaj High Way, Iran, Tel: 98218892 5071; E-mail: frouz@nigeb.ac.ir

Received February 04, 2014; Accepted March 28, 2014; Published March 31 2014

Citation: Shabani S, Mahjoubi F, Mahjoubi B, Mirzaee R (2014) Investigation of hTERT Expression Level and its Relation with Clinicopathological Features and Resistance to Chemotherapy in Colorectal Cancer Patients. J Mol Biomark Diagn 5: 176. doi:10.4172/2155-9929.1000176

Copyright: (c) 2014 Shabani S, et al. This is an open-access article distributed under the terms of the Creative Commons Attribution License, which permits unrestricted use, distribution, and reproduction in any medium, provided the original author and source are credited 
Citation: Shabani S, Mahjoubi F, Mahjoubi B, Mirzaee R (2014) Investigation of hTERT Expression Level and its Relation with Clinicopathological Features and Resistance to Chemotherapy in Colorectal Cancer Patients. J Mol Biomark Diagn 5: 176. doi:10.4172/2155-9929.1000176

Page 2 of 4

or computer tomography scan (CT) every 6 month intervals thereafter. Patients with elevated CEA, clinical sign such as pain, and bleeding, with no decrease in tumor size, or metastasis considered as nonresponsive [15]

\section{RNA extraction and cDNA synthesis}

RNA extraction was carried out by Tripure Isolation Reagent (Roch applied sciences). For cDNA synthesis, $1 \mu \mathrm{g}$ of total RNA from each sample was used to synthesize first-strand cDNA according to the manufacturer's protocol (Frementas).

\section{Real-time RT-PCR}

Evaluation of the expression level of telomerase was performed by Real-Time quantitative PCR using a lightcycler ${ }^{\mathrm{TM}}$ system (Corbett Real Time Thermal cycler) and Fast-Start DNA Master SYBR-Green I kit (Roche Applied Sciences) using GAPDH as a housekeeping gene.

The PCR was performed in $10 \mu \mathrm{L}$ of solution, consisting of $2 \mu \mathrm{L}$ of Fast Start Master solution and $0.5 \mu \mathrm{M}$ of each primer. A total of $13 \mu \mathrm{L}$ of this reaction mix was placed into 0.1 vials, and $2 \mu \mathrm{L}$ of cDNA was added as a template.

The following primers were used for evaluating hTERT expression: hTERT Forward 5'AGTGTGTACGTGGTCGAGCTG3' and hTERT -Reversed 5'GGGGATGAAGCGGAGTCT3'. The primer sequences for GAPDHwereasfollows: Forward5'GCAGGGGGGAGCCAAAAGGG3' and Reverse $5^{\prime}$ TGGGTGGCAGTGATGGCATGG 3'. Thermal cycling consisted of an initial denaturation step $95^{\circ} \mathrm{C}$ for min followed by an amplification program (primer annealing, amplification and quantification) repeated for 40 cycles. The amplification program was $95^{\circ} \mathrm{C}$ for $10 \mathrm{Sec}, 59^{\circ} \mathrm{C}$ for $15 \mathrm{Sec}$ and $72^{\circ} \mathrm{C}$ for $20 \mathrm{Sec}$ with a single fluorescence acquisition at the end of the elongation step. The third segment consisted of a melting curve program at $95^{\circ} \mathrm{C}$ for $0 \mathrm{Sec}, 70^{\circ} \mathrm{C}$ for $10 \mathrm{Sec}$ and $95^{\circ} \mathrm{C}$ for $0 \mathrm{Sec}$ with a linear temperature transition rate of $0.1^{\circ} \mathrm{C} / \mathrm{Sec}$ with continuous fluorescence acquisition. Finally, a cooling program cooled the reaction mixture to $40^{\circ} \mathrm{C}$.

\section{Statistic analysis}

The raw data from Real time RT-PCR analyzed with linreg software. This software computes the efficiency and Crossing Threshold (CT) for each reaction. Statistical analysis was performed using the SPSS for software V18.0 (SPSS, Inc., Chicago, IL). Differences between groups were analyzed by One-Way Analysis of Variance (ANOVA) and the Turkey multiple comparison tests. A $\mathrm{P}$ value less than 0.05 were considered statistically significant.

\section{Results}

\section{Patients' clinical and pathological data}

In total 50 colon cancer patients were studied ( 23 women and 27 men). Individuals whose follow up were not available $(n=5)$ were excluded from final analysis. The average age of the patients was 57 years. Stage I, II, and III IV were diagnosed by pathology examination in $28 \%, 26 \%, 26 \%$ and $20 \%$ of the patients, respectively. Most of the patients had tumor size smaller than $5 \mathrm{~cm}(\mathrm{n}=24,48 \%)$, about $32 \%$ $(\mathrm{n}=16)$ of the patients had tumor size between $5-8 \mathrm{~cm}$, while $20 \%$ of the patients had tumors size larger than $10 \mathrm{~cm}(\mathrm{n}=10,20 \%)$. Twenty three $(46 \%)$ of the patients had lymph node metastasis. The patients were divided into two groups according to the results of chemotherapy. Patients who had response formed the positive response group, while patients who showed no response made up the negative chemotherapy response group. Forty four patients had response (88\%) and six patients had no response (12\%).

\section{Association between clinicopathological features and hTERT expression level}

In the present study the possible association between telomerase expression level and clinicopathological features was investigated .According to the data results there was a significant correlation between hTERT expression level and tumor stage in colorectal cancer. So that the highest expression level was in stage 1 of this cancer $(\mathrm{P}>0.05)$ (Figure 1).

No significant relation was observed between expression level of hTERT and gender, age, tumor size, lymph node involvement, chemotherapy response. The summary of the data are summarized in Table 1.

\section{Real-time PCR validation}

For the mRNA expression analysis of telomerase gene and the housekeeping gene a reliable and reproducible relative quantification method based on Light Cycler ${ }^{\mathrm{TM}}$ technology and linreg software was established and validated. Melting curve analysis showed only one peak for each reaction and this also confirmed by electrophoresis of PCR products that showed only one band of the expected size.

The amplification curves, melting curve and PCR products are illustrating for hTERT and GAPDH in Figure 2 and 3.

\section{Expression of hTERT in normal and tumoral colon cancer}

hTERT expression was detected in all the tumoral tissues while it was negative in all adjacent normal tissues, so that there was a significant up-regulation of hTERT mRNA in colorectal cancer tissues

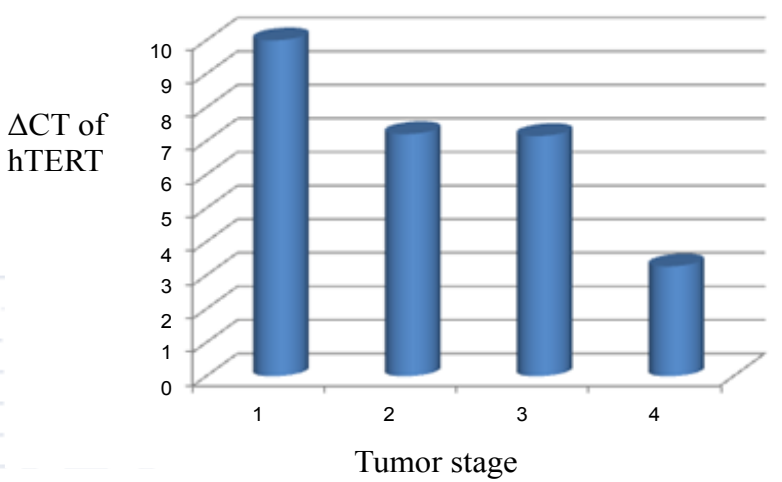

Figure 1: Different $\triangle C T$ in different stages ( $\triangle C T$ between $h T E R T / G A P D H$ mRNA levels in different stages).

\begin{tabular}{|l|l|}
\hline & Expression of hTERT \\
\hline Age & NS $(P>0.05)$ \\
\hline Gender & NS $(P>0.05)$ \\
\hline Tumor size & NS $(P>0.05)$ \\
\hline Lymph node involvement & NS $(P>0.05)$ \\
\hline Histological grade & S $(P<0.05)$ \\
\hline Drug resistance & NS $(P>0.05)$ \\
\hline
\end{tabular}

Table 1: The correlation between hTERT gene expression with clinicopathological features of patients (NS: no significantly important, s: significantly important). 
Citation: Shabani S, Mahjoubi F, Mahjoubi B, Mirzaee R (2014) Investigation of hTERT Expression Level and its Relation with Clinicopathological Features and Resistance to Chemotherapy in Colorectal Cancer Patients. J Mol Biomark Diagn 5: 176. doi:10.4172/2155-9929.1000176

Page 3 of 4
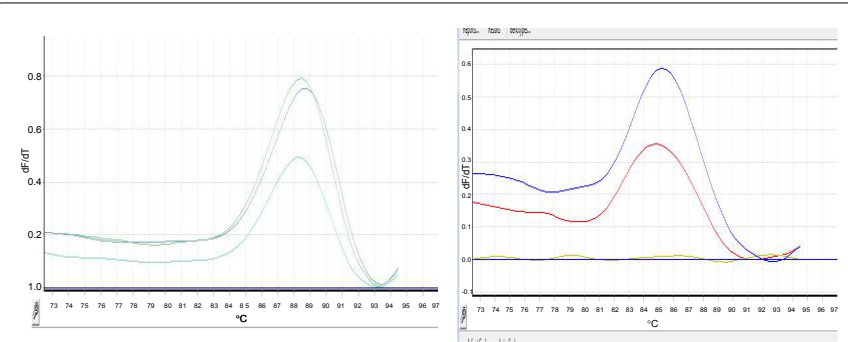

Figure 2: The melting curves of hTERT and GAPDH
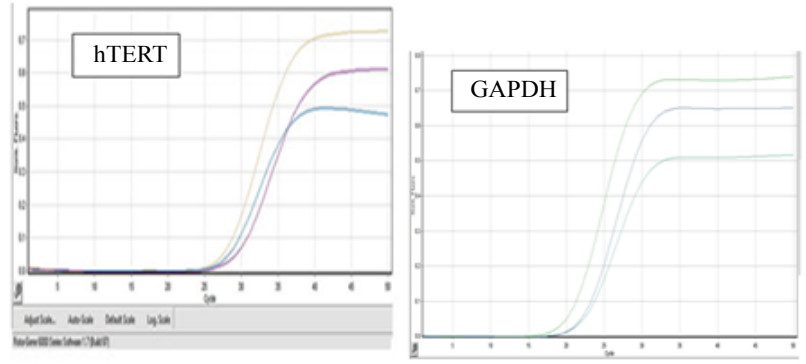

Figure 3: The amplification curves of hTERT and GAPDH.

compared with their normal counterparts. All the patients clinical and molecular data are presented in appendix 1.

\section{Correlation between mRNA expression of hTERT and response to chemotherapy}

A comparison between the tumors of responder vs. non responder patients with respect to the relative expression levels of hTERT showed that there was no significant difference in the expression level of hTERT between patients who were resistant to chemotherapy and sensitive patients (Figure 4).

\section{Discussion}

One of the most common causes of the mortality in the world is cancer. In spite of progressions/advancement in cancer treatments, the clinical outcome is far away from expectation yet [16]. The advent and development of multidrug resistance is a major obstacle which limits the efficiency of chemotherapy in cancers.

Cancer cells are unregulated growth of cells that fail to notice the message to stop growing and one of the main reasons for the failure in cancer treatment is immortalization [5,17]. On the other hand it has been demonstrated that telomerase activity to be increased in proliferative cells like basal, germ , stem cells as compared to normal tissues [18].

According to the above description, this study was conducted to investigate possible association between telomerase expression and clinicopathological features as well as the feasible correlation between telomerase expression and clinical response to chemotherapy in Iranian colorectal cancer patients. The role of telomerase in inducing drug resistance in several cancers has been extensively investigated but the results are not conclusive [11-13].

Human cancers develop resistant to chemotherapeutic drugs with an approximate result of $40 \%$ [19]. Overcoming this event needs the understanding of multidrug resistance mechanism. Furthermore, at the beginning of the chemotherapy only small portion of the cancer cells become resistant to drugs. However, their population becomes dominant when drug resistance occurs [20].

Therefore, we speculated whether or not the resistant cells need more telomerase to help them to proliferate faster and so become the majority of the tumor cells. Previous studies recommended that a high telomerase activity helped maintain or increase drug resistance in colorectal cancer cell lines cultivated with anticancer drugs $[18,21]$. Ward and Autexier [14] showed that telomerase inhibition could sensitize drug resistant cells to chemotherapeutic therapy. Cerone et al. [22] also demonstrated that telomerase inhibition increased the response to anticancer drug treatment in human breast cancer cell lines.

In contrast, another report showed that there was no significant difference between drug resistant and sensitive MCF-7 cells in hTERT expression levels and telomerase [13].

Among 50 CRC patients enrolled in this study 10 persons had recurrence of cancer and were resistant to chemotherapy. We found no significant difference in the expression level of hTERT between patients who were resistant to chemotherapy and sensitive patients.

Therefore, by this evidence we may comment that resistance to chemotrapeutic drugs is independent of the hTERT expression and multidrug resistant does not seem to have a direct association with expression levels of hTERT. This study was also conducted to investigate the association between telomerase mRNA level and clinicopathological features.

1-Age: The risk of colorectal cancer increases with advancing age. More than $90 \%$ of cases occur in people aged 50 or older [22]. We assumed that there may be a correlation between hTERT expression levels and patient ages. The age range of the patients studied was between 26 to 88 . The analysis between hTRET expression levels and age of patients illustrated that this association was not significant.

2-Tumor size: Studies have shown that an increase in tumor size relates to an increased risk of recurrence in the most cancers [23-25]. In breast cancer tumor size is a very important factor in predicting clinical outcomes [26]. Hoos et al. [27] have also found a significant correlation between telomerase activity and tumor size in breast cancer in drug resistant MCF-7 cell. In contrast, another study showed the tumor size was independent telomerase expression [27].

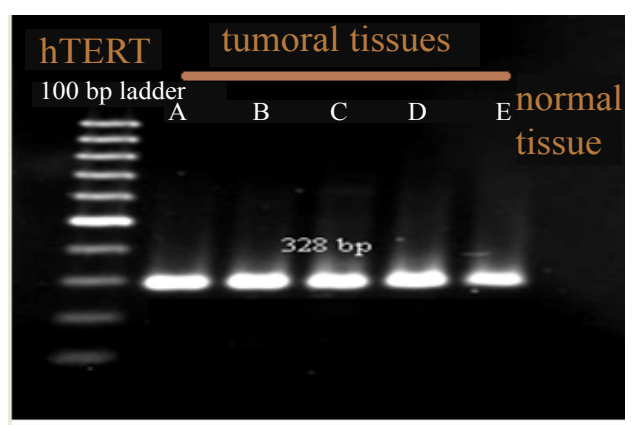

Figure 4: Telomerase expression in tumoral and adjacent normal tissues. (A $\mathrm{B}, \mathrm{C}, \mathrm{D}, \mathrm{E}$ are tumoral and $\mathrm{F}$ column normal tissue 
Citation: Shabani S, Mahjoubi F, Mahjoubi B, Mirzaee R (2014) Investigation of hTERT Expression Level and its Relation with Clinicopathological Features and Resistance to Chemotherapy in Colorectal Cancer Patients. J Mol Biomark Diagn 5: 176. doi:10.4172/2155-9929.1000176

Page 4 of 4

In the present study most of the patients had tumor size smaller than $5 \mathrm{~cm}(\mathrm{n}=24,48 \%)$, about $32 \%(\mathrm{n}=16)$ of the patients had tumor size between $5-8 \mathrm{~cm}$, while $20 \%$ of the patients had tumors size larger than $10 \mathrm{~cm}(\mathrm{n}=10,20 \%)$. Our results indicated that there was no relation between tumor size and the telomerase expression level

3-Lymph node involvement: The involvement of lymph nodes by tumor is an important factor in determining prognosis in gastric cancer [28]. It has been illustrated by Okayasu that telomerase activity is associated with lymph node metastasis in colorectal carcinomas [29]. On the contrary, other studies did not confirm these results and described no relation between telomerase activity and prognostic indicators such as lymph nodes [30]. In the present study data analysis showed that hTERT expression level was not correlated with lymph node involvement.

4-Histological grade: Tumor grade is also an important prognostic variable. Histologic grade called differentiation, refers to how much the tumor cells resemble normal cells of the same tissue type [31]. Since this factor has an important role in cancer prognosis and treatment in this study the relation between hTERT mRNA level and histological grade of tumor was also investigated. Our results revealed that telomerase (hTERT) expression level was correlated with the stage of the colorectal cancer $(\mathrm{P}<0.05)$. hTERT expression level was significantly increased in early stage tumors. Tumors in stage I had the most expression level in comparison with other stages. One possible interpretation is that in early stages of tumor formation, most tumors indicate continuous telomers shortening. When telomers become critically short, this cause telomerase activation.

In conclusion, these findings demonstrate the importance of telomerase for tumorgenesis and possibly indirectly in drug resistance and it can be used as molecular marker for cancer diagnosis. The controversial results which are obtained from several studies may be partly due to the presence of an Alternative Lengthening of Telomers (ALT) mechanism, different kind of tumoral tissues and diverse common practical methods applied for investigation of gene expression [32].

\section{Acknowledgements}

This project was supported by a NIGEB grant. The authors would like to thank all patients who willingly participated in the study.

\section{References}

1. Center MM, Jemal A, Smith RA, Ward E (2009) Worldwide variations in colorectal cancer. CA Cancer J Clin 59: 366-378.

2. Stewart SA, Hahn WC, O'Connor BF, Banner EN, Lundberg AS, et al. (2002) Telomerase contributes to tumorigenesis by a telomere length-independent mechanism. Proc Natl Acad Sci U S A 99: 12606-12611.

3. Esna-Ashari F, Sohrabi MR, Abadi A, Mehrabian AA, Mofid B, et al. (2012) Colorectal cancer prevalence according to survival data in Iran-2007. Iranian Journal of Cancer Prevention 2: 15-18.

4. Pourhoseingholi MA, Zali MR (2012) Colorectal cancer screening: Time for action in Iran. World J Gastrointest Oncol 4: 82-83.

5. Ozben T (2006) Mechanisms and strategies to overcome multiple drug resistance in cancer. FEBS Lett 580: 2903-2909.

6. Liu YY, Gupta V, Patwardhan GA, Bhinge K, Zhao Y, et al. (2010) Glucosylceramide synthase upregulates MDR1 expression in the regulation of cancer drug resistance through cSrc and beta-catenin signaling. Mol Cancer 9: 145.
7. Hanahan D, Weinberg RA (2011) Hallmarks of cancer: the next generation Cell 144: 646-674.

8. Blasco MA (2005) Telomeres and human disease: ageing, cancer and beyond Nat Rev Genet 6: 611-622.

9. Shay JW, Wright WE (2000) Hayflick, his limit, and cellular ageing. Nat Rev Mol Cell Biol 1: 72-76.

10. Neumann AA, Reddel RR (2002) Telomere maintenance and cancer -- look, no telomerase. Nat Rev Cancer 2: 879-884.

11. Hiyama K (2009) Telomeres and telomerase in cancer. Cancer Drug Discovery and Development.

12. Chatziantoniou VD (2001) Telomerase: biological function and potential role in cancer management. Pathol Oncol Res 7: 161-170.

13. Kuranaga N, Shinomiya N, Mochizuki H (2001) Long-term cultivation of colorectal carcinoma cells with anti-cancer drugs induces drug resistance and telomere elongation: an in vitro study. BMC Cancer 1: 10.

14. Ward RJ, Autexier C (2005) Pharmacological telomerase inhibition can sensitize drug-resistant and drug-sensitive cells to chemotherapeutic treatment. Mo Pharmacol 68: 779-786.

15. Sakin V, Eskiocak U, Kars MD, Iseri OD, Gunduz U (2008) hTERT gene expression levels and telomerase activity in drug resistant MCF-7 cells. Exp Oncol 30: 202-205.

16. Sobin LH, MK Gospodarowicz, C Wittekind (2009) TNM classification of malignant tumours, (7thedn) Wiley-Blackwell.

17. Baguley BC (2010) Multidrug resistance in cancer. Multi-drug resistance in cancer 596: 1-14.

18. Dervenis C, E Xynos (2007) Colorectal Cancer: S Karger Ag

19. Meyerson M (2000) Role of telomerase in normal and cancer cells. J Clin Oncol 18: $2626-2634$

20. Higgins CF (2007) Multiple molecular mechanisms for multidrug resistance transporters. Nature 446: 749-757.

21. Zhou J, Multi-Drug Resistance in Cancer 2010: Humana Press

22. Cerone MA, Londoño-Vallejo JA, Autexier C (2006) Telomerase inhibition enhances the response to anticancer drug treatment in human breast cancer cells. Mol Cancer Ther 5: 1669-1675.

23. CASES, N.O.I., SEER Cancer Statistics Review 1975-2002. 2004.

24. Yarbro CH, Wujcik D, Gobel BH (2011) Cancer Nursing: Principles and Practice 2010: Jones \& Bartlett Learning.

25. Carter CL, Allen C, Henson DE (1989) Relation of tumor size, lymph node status, and survival in 24,740 breast cancer cases. Cancer 63: 181-187.

26. Foulkes WD, Reis-Filho JS, Narod SA (2010) Tumor size and survival in breast cancer--a reappraisal. Nat Rev Clin Oncol 7: 348-353.

27. Hoos A, Hepp HH, Kaul S, Ahlert T, Bastert G, et al. (1998) Telomerase activity correlates with tumor aggressiveness and reflects therapy effect in breast cancer. Int J Cancer 79: 8-12.

28. Tang R, Cheng AJ, Wang JY, Wang TC (1998) Close correlation between telomerase expression and adenomatous polyp progression in multistep colorectal carcinogenesis. Cancer Res 58: 4052-4054.

29. Yokota T, Ishiyama S, Saito T, Teshima S, Narushima Y, et al. (2004) Lymph node metastasis as a significant prognostic factor in gastric cancer: a multiple logistic regression analysis. Scand J Gastroenterol 39: 380-384.

30. Okayasu I, Mitomi H, Yamashita K, Mikami T, Fujiwara M, et al. (1998) Telomerase activity significantly correlates with cell differentiation, proliferation and lymph node metastasis in colorectal carcinomas. J Cancer Res Clin Oncol 124: 444-449.

31. Wisman GB, Knol AJ, Helder MN, Krans M, de Vries EG, et al. (2001) Telomerase in relation to clinicopathologic prognostic factors and survival in cervical cancer. Int J Cancer 91: 658-664.

32. Barbara L Gordon, Heather S Shaw, David J Kroll, Brooke R Daniel (2010) Breast Cancer Recurrence and Advanced Disease: Comprehensive Expert Guidance: Duke University Press. 